\title{
The Incidental Adrenal Mass on Computed Tomography
}

\author{
Khalid S Aljabri*, Ibrahim M Alnasser ${ }^{2}$, Samia A Bokhari', Saad Zuair², Waleed 0 Bawzeer ${ }^{1}$ and Mohammad A \\ Melibari $^{1}$
}

${ }^{1}$ Department of Endocrinology, King Fahad Armed Forces Hospital, Jeddah, Kingdom of Saudi Arabia

${ }^{2}$ Department of Radiology, King Fahad Armed Forces Hospital, Jeddah, Kingdom of Saudi Arabia

*Corresponding author: Khalid S. Aljabri, Department of Endocrinology, King Fahad Armed Forces Hospital, Jeddah, Kingdom of Saudi Arabia

\begin{abstract}
Background: The widespread use of computed tomography (CT) has resulted in the frequent incidental discovery of asymptomatic adrenal masses. The aim of the present study was to report retrospectively a 4-year CT studies of the frequency of adrenal incidentalomas (AI) in a tightly defined geographical area in Jeddah, Saudi Arabia.

Design: This retrospective study was approved by our institutional review board, and informed consent was waived. The CT reports of 15,600 abdominal CT examinations from our institution at King Fahad Armed Forces Hospital, Jeddah, Saudi Arabia performed from January 2015 to December 2018 were searched for the word "adrenal" in the impression. The search identified 87 patients with adrenal lesions which constituted the subject material for the study.

Results: During a 4 -year period, a total of $87(0.6 \%)$ patients were diagnosed with AI and included in the study. Demographic characteristics were as follows: $37(43 \%)$ males and 50 (58\%) females, aged between 30-87 years (median, 58 years and mean \pm SD $58.7 \pm 13.6$ years). Fifty-five percent of the subjects were in their $50 \mathrm{~s}$ and $60 \mathrm{~s}$. AI in males were more frequent in the fourth, eighth and ninth decades whereas $\mathrm{AI}$ in females were more frequent in fifth and seventh decades. AI were more frequent on the left [47 (54\%)] than on the right side [28 (32.3\%)], whereas bilateral AI were found in 12 [(13.8 \%)] patients. Moreover, AI in males were more frequent on the right [17 (45.9\%)] than on the left side [11 $(22.0 \%)]$, whereas AI in females were more frequent on the left $15(40.5 \%)$ than on the right side $32(64.0 \%)$ and slightly more frequent in bilateral sites (14\% vs. $13.5 \%)$, $p=0.05$. The size of the right-sided AI $(1.9 \pm 1.3 \mathrm{~cm})$ were non-significantly larger than the left-sided ones $(1.6 \pm 0.8 \mathrm{~cm}), \mathrm{p}=0.2$.In the overall series, the diameter of the AI estimated by CT ranged from 0.5-7.9 cm; (median, $1.7 \mathrm{~cm}$ and mean $1.8 \pm 1.1 \mathrm{~cm}$ ) where the largest number of patients with AI were seen in 8 cases (11.7\%) at size of $1.7 \mathrm{~cm}$. Most lesions [ 60 cases (69\%)] were less than $2.0 \mathrm{~cm}$, whereas the mean size of bilateral AI in the dominant mass $(2.3 \mathrm{~cm})$ was larger than mean size of right $(1.9 \mathrm{~cm})$ or left $(1.6 \mathrm{~cm})$ AI. The frequency of AI more than $4 \mathrm{~cm}$ was higher in the right side (50\%) and the dominant mass in the bilateral $\mathrm{AI}(50 \%)$ within the size of $\mathrm{AI}$ groups whereas the frequency of AI less than $2 \mathrm{~cm}$ was higher in the right side of AI (57\%). The mean size of AI was larger in the sixth decade compared to other age groups whereas males $(2.1 \mathrm{~cm})$ and females $(2.7 \mathrm{~cm})$ have higher mean size of AI in the fourth and sixth decade respectively. A negative non-statistically significant correlation was found between age and mass size ( $\mathrm{r}=-0.132$, $\mathrm{p}=0.2$ ). In addition, a positive non-statistically significant correlation was found between BMI and AI size ( $r=-0.066, \mathrm{p}=0.6)$.
\end{abstract}

Conclusion: In conclusion, the current study indicated low prevalence of AI as indicated by CT. In the absence of registry data, larger cooperative studies involving diverse population samples from multiple centers could help to provide further information on the true frequency nationally.

Keywords: Prevalence of adrenal incidentaloma

\section{Introduction}

Adrenal masses are among the most prevalent human tumors and are frequently detected unexpectedly by an imaging study performed for reasons unrelated to suspect of adrenal diseases.

The widespread use of computed tomography (CT) has resulted in the frequent incidental discovery of asymptomatic adrenal masses [1,2]. Adrenal incidentalomas (AI) raise challenging questions for 
both physicians and their patients and represent one of the leading reasons for seeking endocrinological consultation. Although, in most cases, these masses are non-hypersecreting and benign, they still represent an important clinical concern because of the risk of malignancy or hormone hyperfunction. The prevalence of AI varies according to the inclusion criteria of the study and the circumstances under which patient data are collected with a common range of approximately $0.5-4 \%$ of all such investigations [3-9]. This rate is probably underestimated because adrenal adenomas were found in up to $10 \%$ of patients autopsy series without any pre-mortem suspicion of adrenal disease [4,5,10-12].

Although, by definition, adrenal masses discovered in the course of abdominal imaging performed for staging of cancer are not generally considered as $\mathrm{AI}$, several authors include patients with known malignancies in their series. In such patients the risk of an adrenal mass being a metastasis is high, ranging from 45 to $73 \%[7,13,14]$. The economic aspect of the problem has not to be underestimated, because the detection of adrenal masses as an incidental finding with imaging techniques will be ever growing in the future, and an extensive endocrine work-up is required to recognize hormonal abnormalities. The aim of the present study was to report retrospectively a 4-year CT studies of the frequency of AI in a tightly defined geographical area in Jeddah, Saudi Arabia.

\section{Methods}

This retrospective study was approved by our institutional review board, and informed consent was waived. The CT reports of 15,600 abdominal CT examinations from our institution at King Fahad Armed Forces Hospital, Jeddah, Saudi Arabia performed from January 2015 to December 2018 were searched for the word "adrenal" in the impression. Patient CT reports with ambiguous findings (e.g., possible adrenal nodule, probable adrenal adenoma) were excluded. Only the CT estimate of the mass size was considered for statistical analysis. Patients with adrenal lesions on initial CT who were diagnosed with malignancy after the initial CT were included in the study cohort. The search identified 87 patients with adrenal lesions which constituted the subject material for the study. Information was collected from two resources such as clinical case records of subjects seen at the endocrinology or other services and the data on hormonal analysis including neurodynamic tests of the subjects. All endocrine evaluations showed non-hypersecreting adrenal masses. Imaging characteristics were reported on the basis of radiologists' descriptions.

\section{Statistical Analysis}

Data are presented as means \pm standard deviation (SD) or numbers (\%). Quantitative variables were compared between two groups by using the Student's test. Differences in categorical variables were analyzed using the chi-square test. The relationship between continuous variables was assessed using coefficients of correlation. $\mathrm{P}$ value $<0.05$ indicates significance. The statistical analysis was conducted with SPSS version 23.0 for Windows.

\section{Results}

During a 4-year period, a total of $87(0.6 \%)$ patients were diagnosed with $\mathrm{AI}$ and included in the study. Demographic characteristics were as follows: 37 (43\%) males and 50 (58\%) females, aged between 30-87 years (median, 58 years and mean \pm SD 58.7 \pm 13.6 years) (Table 1 ). Fifty-five percent of the subjects were in their 50s and 60s (Figure 1). AI in males were more frequent in the fourth, eighth and ninth decades whereas AI in females were more frequent in fifth and seventh decades (Figure 2). The reasons for an abdominal imaging procedure were renal colic (33\%), abdominal pain (13\%), liver lesions (8\%), intestinal obstruction (2.3\%), abdominal trauma (1.1\%) and others (43\%). In the overall series, obesity in 36 (51\%; missing, 18\%), type 2 diabetes in 42 (48\%) and hypertension was observed in 39 (45\%) patients.

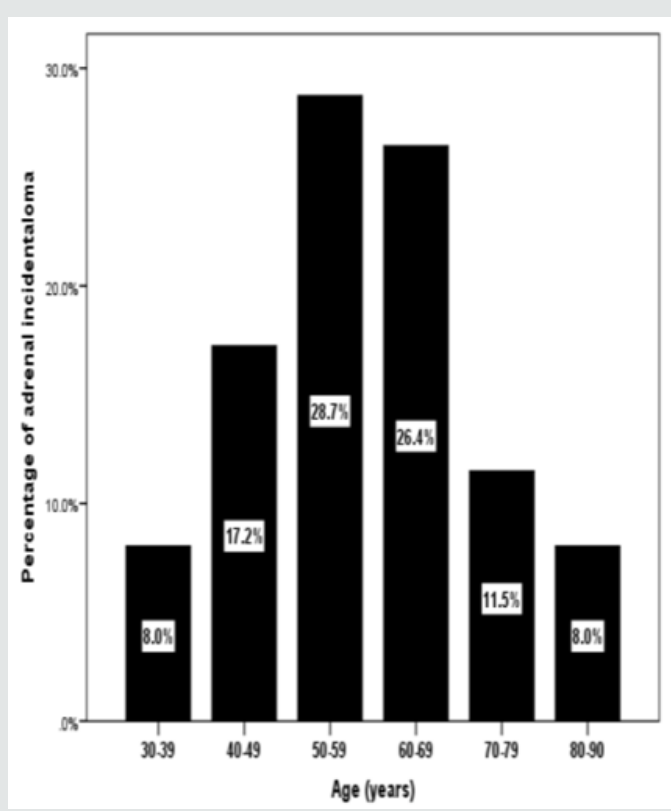

Figure 1: Age distribution of patients in the study.

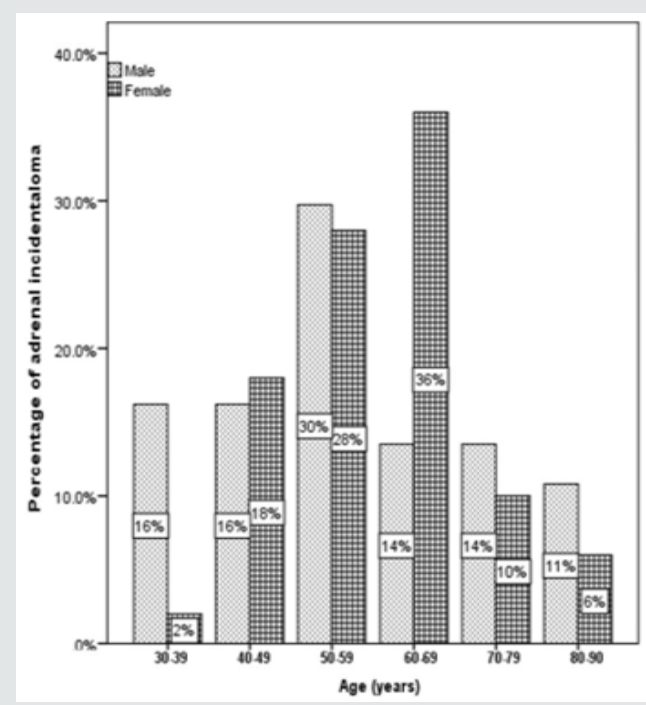

Figure 2: Percentage of adrenal incidentaloma in correlation to age groups according to gender. 
Table 1: Demographics of patients in the study (Data are number (\%) and mean \pm standard deviation).

\begin{tabular}{|c|c|c|}
\hline \multicolumn{2}{|c|}{ Parameters } & Values \\
\hline \multicolumn{2}{|c|}{ Total } & 87 \\
\hline \multicolumn{2}{|c|}{ Age (years) } & $58.7 \pm 13.6$ \\
\hline \multirow{2}{*}{ Gender } & Male & $37(42.5)$ \\
\hline & Female & $50(57.5)$ \\
\hline \multicolumn{2}{|c|}{ Body mass index $\left(\mathrm{kg} / \mathrm{m}^{2}\right)$} & $31.2 \pm 6.6$ \\
\hline \multicolumn{2}{|c|}{ Type 2 diabetes } & $42(48.3)$ \\
\hline \multicolumn{2}{|c|}{ Hypertension } & $39(44.8)$ \\
\hline \multicolumn{2}{|c|}{ Mass size $(\mathrm{cm})$} & $1.8 \pm 1.1$ \\
\hline
\end{tabular}

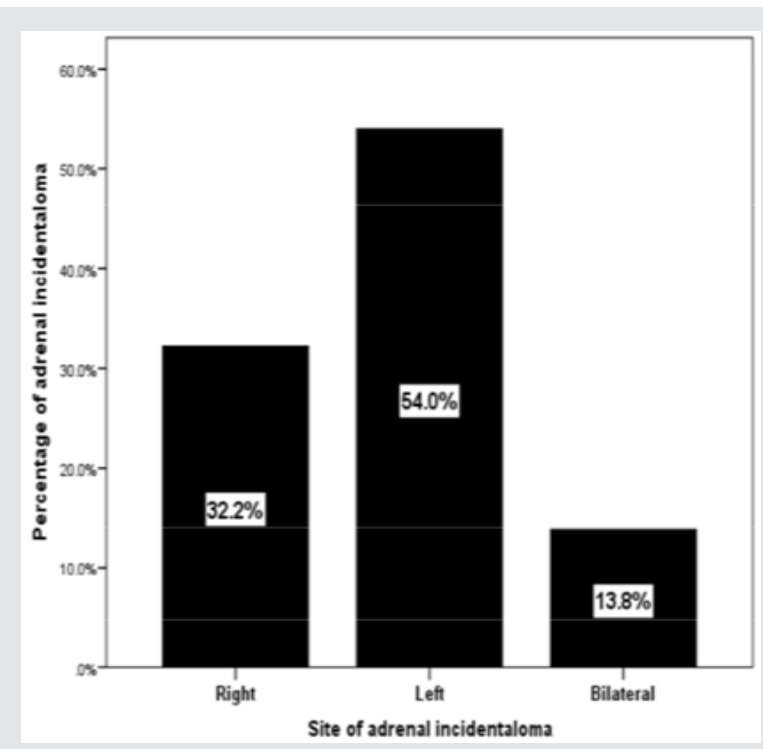

Figure 3: Site distribution of adrenal incidentaloma.

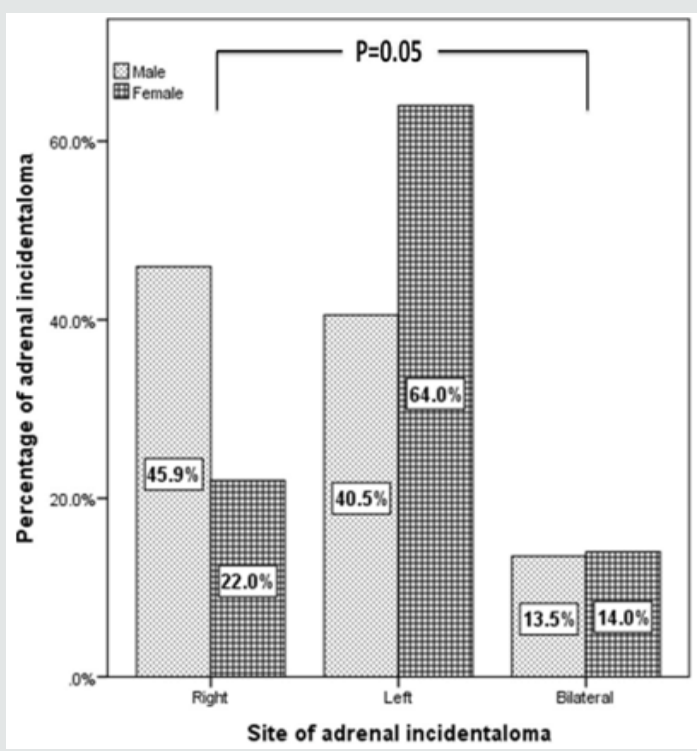

Figure 4: Site distribution of adrenal incidentaloma in correlation to gender.

AI were more frequent on the left [47 (54\%)] than on the right side [28 (32.3\%)], whereas bilateral AI were found in 12 [(13.8\%)] patients (Figure 3). Moreover, AI in males were more frequent on the right [17 (45.9\%)] than on the left side [11 (22.0\%)], whereas $\mathrm{AI}$ in females were more frequent on the left 15 (40.5\%) than on the right side $32(64.0 \%)$ and slightly more frequent in bilateral sites (14\% vs. $13.5 \%$ ), p=0.05 (Figure 4). The size of the right-sided AI $(1.9 \pm 1.3 \mathrm{~cm})$ were non-significantly larger than the left-sided ones $(1.6 \pm 0.8 \mathrm{~cm}), \mathrm{p}=0.2$.

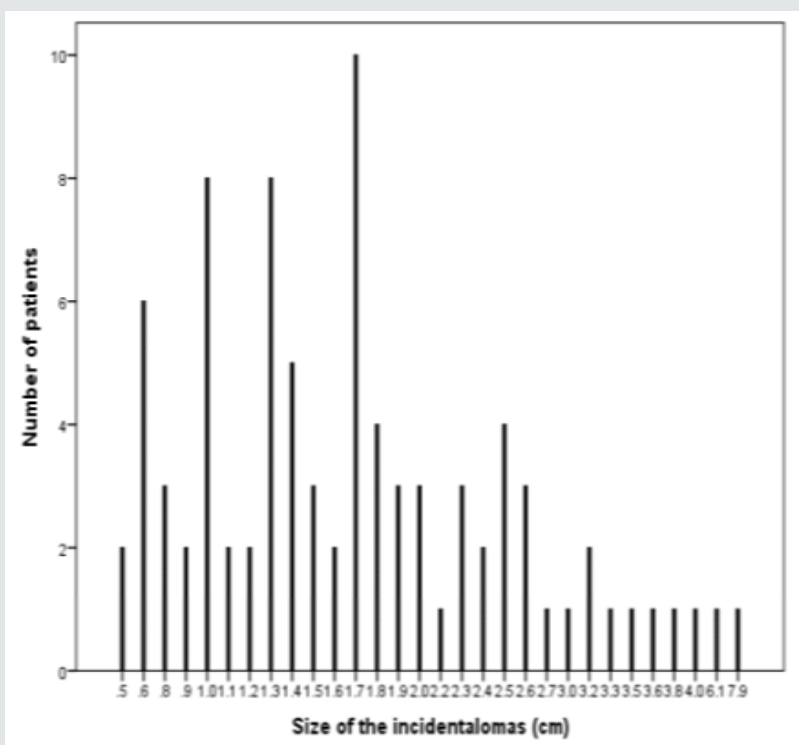

Figure 5: Number of cases distribution in correlation to size of adrenal incidentaloma.

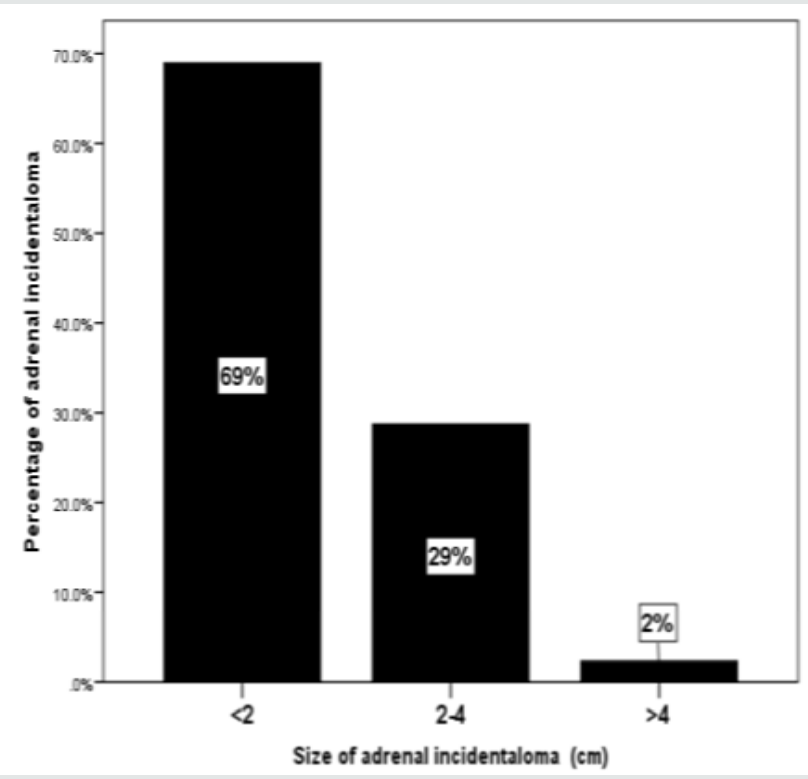

Figure 6: Size distribution of adrenal incidentaloma.

In the overall series, the diameter of the AI estimated by CT ranged from 0.5-7.9 cm; (median, $1.7 \mathrm{~cm}$ and mean $1.8 \pm 1.1 \mathrm{~cm}$ ) where the largest number of patients with AI were seen in 8 cases (11.7\%) at size of $1.7 \mathrm{~cm}$ (Figure 5). Most lesions [60 cases (69\%)] were less than $2.0 \mathrm{~cm}$ (Figure 6), whereas the mean size of bilateral $\mathrm{AI}$ in the dominant mass $(2.3 \mathrm{~cm})$ was larger than mean size of right $(1.9 \mathrm{~cm})$ or left $(1.6 \mathrm{~cm})$ AI (Figure 7). The frequency of AI more 
than $4 \mathrm{~cm}$ was higher in the right side (50\%) and the dominant mass in the bilateral AI (50\%) within the size of AI groups whereas the frequency of $\mathrm{AI}$ less than $2 \mathrm{~cm}$ was higher in the right side of $\mathrm{AI}$ (57\%) (Figure 8). Figure 9 showed the mean size of AI was larger in the sixth decade compared to other age groups whereas males $(2.1 \mathrm{~cm})$ and females $(2.7 \mathrm{~cm})$ have higher mean size of $\mathrm{AI}$ in the fourth and sixth decade respectively (Figure 10). A negative nonstatistically significant correlation was found between age and mass size ( $r=-0.132, p=0.2$ ) (Figure 11). In addition, a positive nonstatistically significant correlation was found between $\mathrm{BMI}$ and $\mathrm{AI}$ size $(r=-0.066, p=0.6)$ (Figure 12).

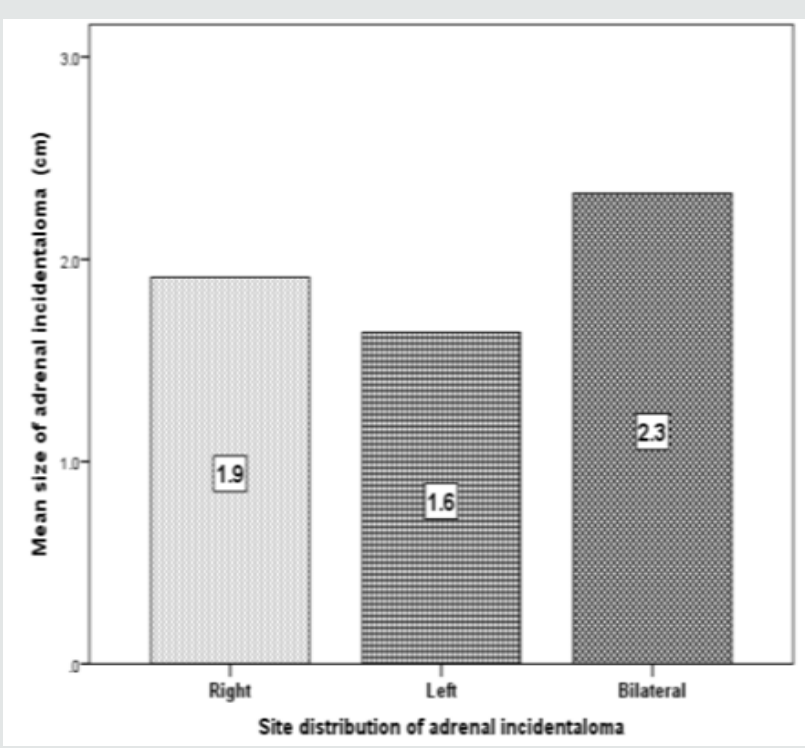

Figure 7: Size distribution of adrenal incidentaloma according to site.

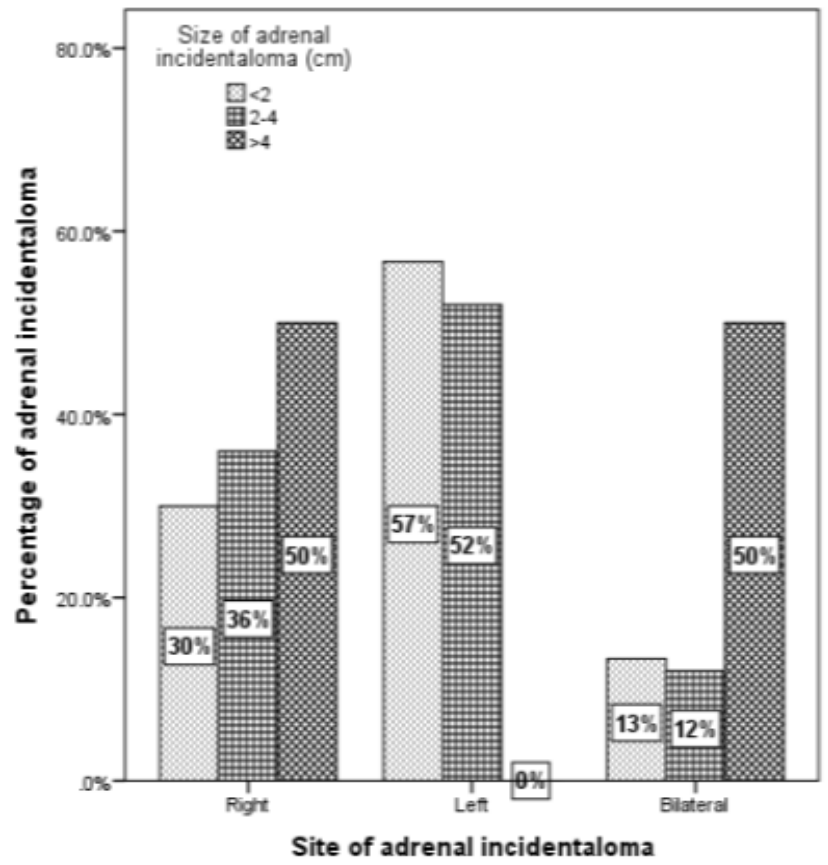

Figure 8: Size distribution of adrenal incidentaloma according to site in correlation to gender.

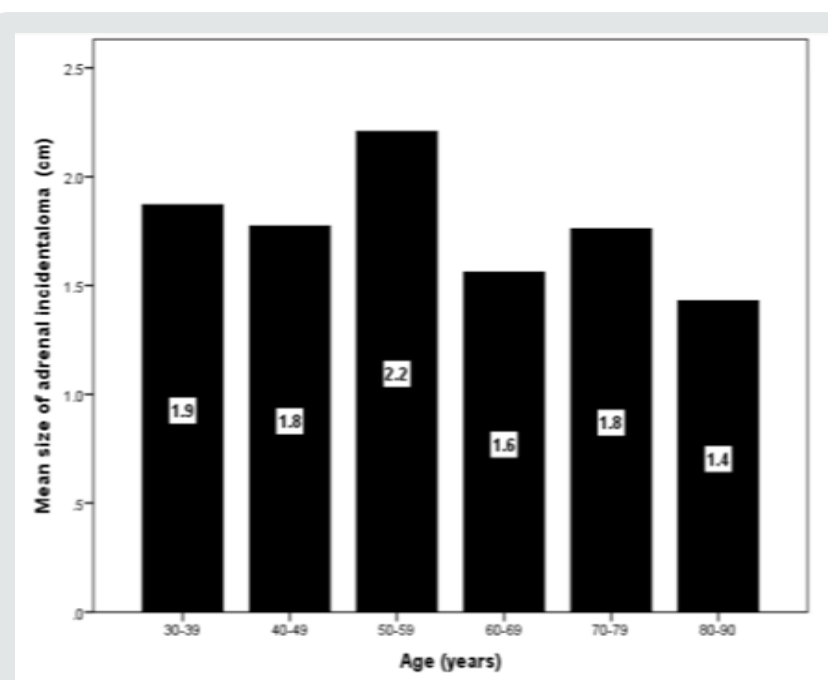

Figure 9: Mean size of adrenal incidentaloma in correlation to age groups.

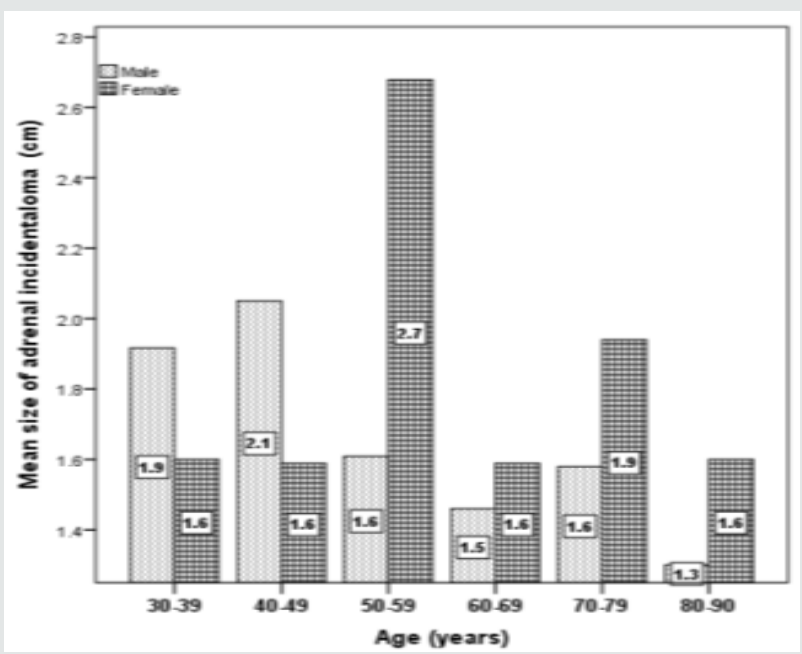

Figure 10: Mean size of adrenal incidentaloma according to gender in correlation to age groups.

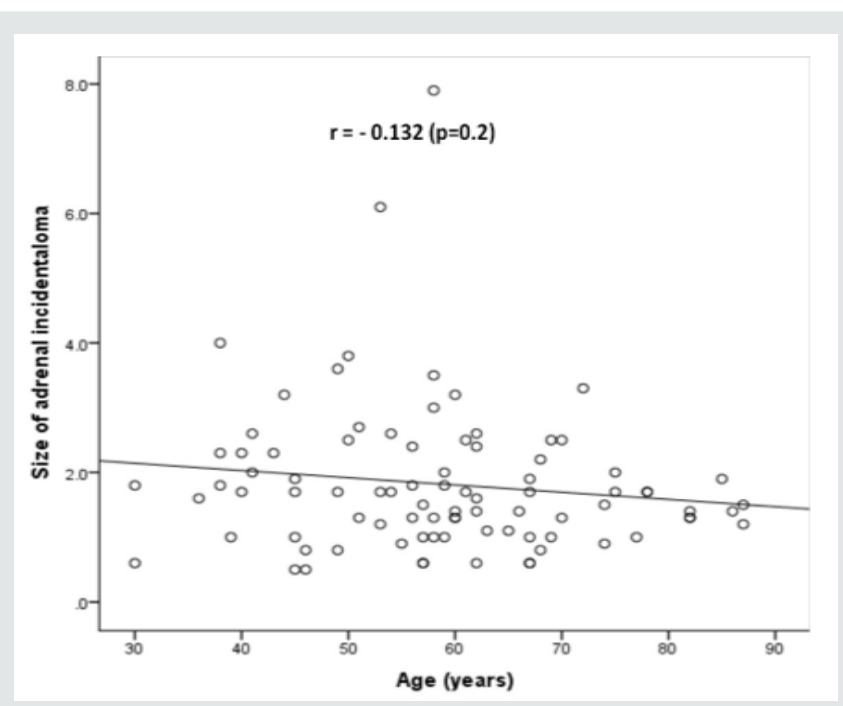

Figure 11: Correlation of size of adrenal incidentaloma and age in the study population. 


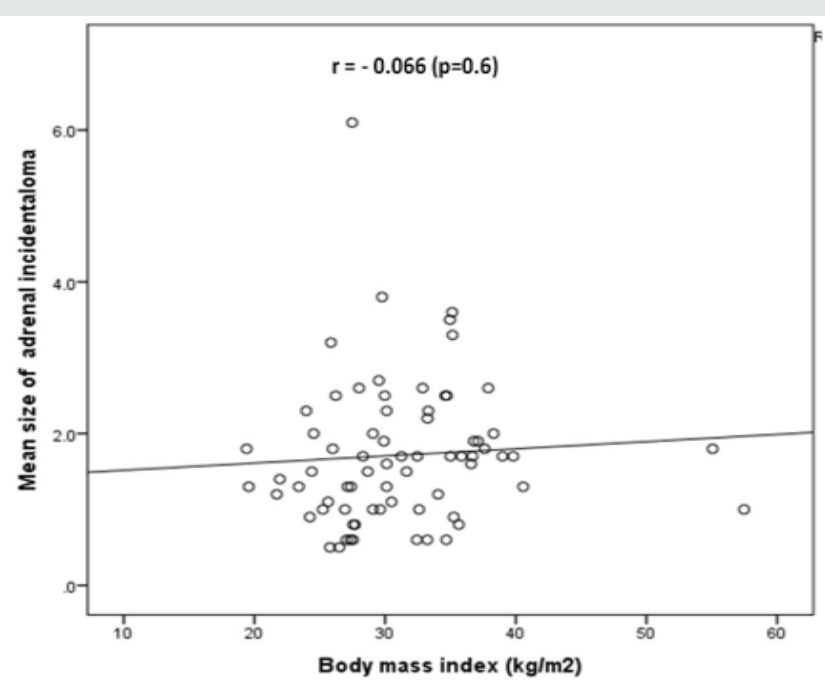

Figure 12: Correlation of size of adrenal incidentaloma and body mass index in the study population.

\section{Discussion}

CT is an accurate tool for detecting the presence of adrenal masses in $97-99 \%$ of patients. Numerous comprehensive reviews on the topic of radio-imaging have been published describing the most common adrenal gland pathologies [3,15-19] Incidental adrenal masses are frequently seen on CT with the increasing use of cross-sectional imaging. With the current high resolution CT scanners, the prevalence of AI has increased, and our result of $0.6 \%$ prevalence corroborates with the $1-2 \%$ reported in the older literature, compared the $4.4 \%$ reported from a recent series $[20,21]$. The prevalence of AI on imaging now approaches that of autopsy series, although not as high as the frequently cited $9 \%$, which includes microscopic lesions [4,22]. Prior studies reporting the pathology of incidentally detected adrenal masses often had selection bias because only surgically resected masses were analyzed $[23,24]$. In addition, the definition of AI is broad among different series, with many studies including oncologic patients [24-26].

The age distribution of the present study is wide, skewed toward older ages, and peaks in the sixth decade, as previously reported [4]. This pattern could merely reflect a higher number of diagnostic procedures in aged patients, or it could be explained by an increased occurrence of cortical nodules with age, as observed in unselected autopsy series $[10,11]$. The higher number of females observed in the present study confirms the results of some large radiological series [7]. This figure could be partly explained by a referral bias (i.e. more imaging studies are recommended for women due to higher prevalence of biliary disease), as nonfunctioning adrenal adenomas occur with comparable frequency in males and females in autopsy series.

In the present study, the majority of AI (69\%) were smaller than $2 \mathrm{~cm}$ in agreement with previous results whereas AI larger than $4 \mathrm{~cm}$ was found in $2 \%$ of our studied population $[23,27-$ 29]. Previous report confirmed that the risk of a primary adrenal malignancy is related to the mass size. 30 The correlation, however, is far from perfect, as different types of adrenal lesions presented as large masses. In the literature, the cut-off points proposed ranged from 2.5- $6.0 \mathrm{~cm}[7,9,30-32]$. The diagnostic value of different cutoff points was evaluated, and a threshold at $4 \mathrm{~cm}$ proved to have the highest sensitivity (93\%); the specificity was low because the rate of benign lesions exceeded that of malignant ones [7,9,30-32]. AI were most frequently found on the left side in disagreement with previous reports which reported no side difference, considering mass number or size, was apparent in the series discovered by CT scan $[5,32,33]$.

We aimed to identify the unapparent adrenal mass as incidentally found by CT scans, and this aim was reflective of the clinical setting because not all AI are formally diagnosed with histological confirmation. Furthermore, due to the retrospective nature of this study, the observed population reflects a selected, yet comprehensive group of patients referred for non-adrenal CT, rather than the general population as would be encountered in an autopsy series. Our study could be limited by the question of clustering of cases within the study region and the effect that might have on our estimates, in addition, the current study population may appear limited in size and therefore may underestimate the true prevalence of AI in the general population. In addition, the study shares the limitations of all retrospective studies. In conclusion, the current study indicated low prevalence of AI as indicated by CT. In the absence of registry data, larger cooperative studies involving diverse population samples from multiple centers could help to provide further information on the true frequency nationally.

\section{References}

1. Gross MD, Shapiro B (1993) Clinical review 50. Clinically silent adrenal masses. J Clin Endocrinol Metab 77(4): 885-888.

2. Chidiac RM, Aron DC (1977) Incidentalomas. A disease of modern technology. Endocrinol Metab Clin North Am 26(1): 233-253.

3. Peppercorn PD, Grossman AB, Reznek RH (1998) Imaging of incidentally discovered adrenal masses. Clin Endocrinol (Oxf) 48(4): 379-388.

4. Kloos RT, Gross MD, Francis IR, Korobkin M, Shapiro B (1995) Incidentally discovered adrenal masses. Endocr Rev 16(4): 460-484.

5. Abecassis M, McLoughlin MJ, Langer B, Kudlow JE (1985) Serendipitous adrenal masses: prevalence, significance, and management. Am J Surg 149(6): 783-788.

6. Prinz RA, Brooks MH, Churchill R, Graner JL, Lawrence AM (1982) Incidental asymptomatic adrenal masses detected by computed tomographic scanning. Is operation required? JAMA 248(6): 701-704.

7. Belldegrun A, Hussain S, Seltzer SE, Loughlin KR, Gittes RF, et al. (1986) Incidentally discovered mass of the adrenal gland. Surg Gynecol Obstet 163(3): 203-208.

8. Caplan RH, Strutt PJ, Wickus GG (1994) Subclinical hormone secretion by incidentally discovered adrenal masses. Arch Surg 129(3): 291-296.

9. Glazer HS, Weyman PJ, Sagel SS, Levitt RG, McClennan BL (1982) Nonfunctioning adrenal masses: incidental discovery on computed tomography. AJR Am J Roentgenol 139(1): 81-85. 
10. Commons RR, Callaway CP (1948) Adenomas of the adrenal cortex. Arch Intern Med 81: 37-141

11. Russi S, Blumenthal HT, Gray SH (1945) Small adenomas of the adrenal cortex in hypertension and diabetes. Arch Intern Med 76(5): 284-291.

12. Kokko JP, Brown TC, Berman MM (1967) Adrenal adenoma and hypertension. Lancet 289(7488): 468-470.

13. Becassis M, McLoughlin MJ, Langer B, Kudlow JE (1985) Serendipitous adrenal masses: prevalence, significance, and management. American Journal of Surgery 149(6): 783-788.

14. Francis IR, Smid A, Gross MD, Shapiro B, Naylor B, et al. (1988) Adrenal masses in oncologic patients: functional and morphologic evaluation. Radiology 166(2): 353-356.

15. Boland GW, Lee MJ, Gazelle GS, Halpern EF, McNicholas MM, et al. (1998) Characterization of adrenal masses using unenhanced CT: an analysis of the CT literature. AJR Am J Roentgenol 171(1): 201-204.

16. Dunnick NR, Korobkin M (2002) Imaging of adrenal incidentalomas: current status. AJR Am J Roentgenol 179(3): 559-568.

17. Korobkin M (2000) CT characterization of adrenal masses: the time has come. Radiology 217(33): 629-632.

18. Mayo-Smith WW, Boland GW, Noto RB, Lee MJ (2001) State-of the- art adrenal imaging. Radio graphics 21(4): 995-1012.

19. Udelsman R, Fishman EK (2000) Radiology of the adrenal. Endocrinol Metab Clin North Am 29(1): 27-42.

20. Bovio S, Cataldi A, Reimondo G, Sperone P, Novello S, et al. (2006) Prevalence of adrenal incidentaloma in a contemporary computerized tomography series. J Endocrinol Invest 29(4): 298-302.

21. Gajraj H, Young AE (1993) Adrenal incidentaloma. Br J Surg 80: 422-426.

22. Barzon L, Sonino N, Fallo F, Palu G, Boscaro M (2003) Prevalence and natural history of adrenal incidentalomas. Eur J Endocrinol 149(4): 273285.

23. Mantero F, Terzolo M, Arnaldi G, Osella G, Masini AM, et al. (2000) A survey on adrenal incidentaloma in Italy. Study Group on Adrenal
Tumors of the Italian Society of Endocrinology. J Clin Endocrinol Metab 85(2): 637-644.

24. Bülow B, Ahrén B (2002) Adrenal incidentaloma: experience of standardized diagnostic programme in the Swedish prospective study. J Intern Med 252(3): 239-246.

25. Mansmann G, Lau J, Balk E, Rothberg M, Miyachi Y, et al. (2004) The clinically inapparent adrenal mass: update in diagnosis and management. Endocr Rev 25(2): 309-340.

26. Benitah N, Yeh BM, Qayyum A, Williams G, Breiman RS, et al. (2005) Minor morphologic abnormalities of adrenal glands at CT: prognostic importance in patients with lung cancer. Radiology 235(2): 517-522.

27. Osella G, Terzolo M, Borretta G, Magro G, Alí A, et al. (1994) Endocrine evaluation of incidentally discovered adrenal masses (incidentalomas). J Clin Endocrinol Metab 79(6): 1532-1539.

28. Ambrosi B, Peverelli S, Passini E, Re T, Ferrario R, et al. (1995) Abnormalities of endocrine function in patients with clinically _silent adrenal masses. Eur J Endocrinol 132(4): 422-428.

29. Oelkers W (1995) Diagnostic puzzle of the adrenal_incidentaloma_. Eur J Endocrinol 132(4): 419-421.

30. Copeland PM (1983) The incidentally discovered adrenal mass. Ann Intern Med 98: 940-945.

31. Ross NS, Aron DC (1990) Hormonal evaluation of the patient with an incidentally discovered adrenal mass. N Engl J Med 323(20): 1401-1405.

32. Herrera MF, Grant CS, Van Heerden JA, Sheedy PF, Ilstrup DM (1991) Incidentally discovered adrenal tumors: an institutional perspective. Surgery 110(6): 1014-1021.

33. Franco Mantero, Massimo Terzolo, Giorgio Arnaldi, Giangiacomo Osella Anna Maria Masini, et al. (2000) A Survey on Adrenal Incidentaloma in Italy. Study Group on Adrenal Tumors of the Italian Society of Endocrinology. The Journal of Clinical Endocrinology \& Metabolism 85(2): 637-644.

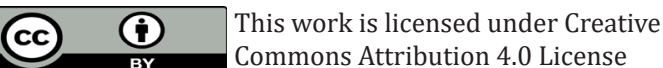

To Submit Your Article Click Here: Submit Article

DOI: $10.32474 / A D 0.2019 .02 .000130$

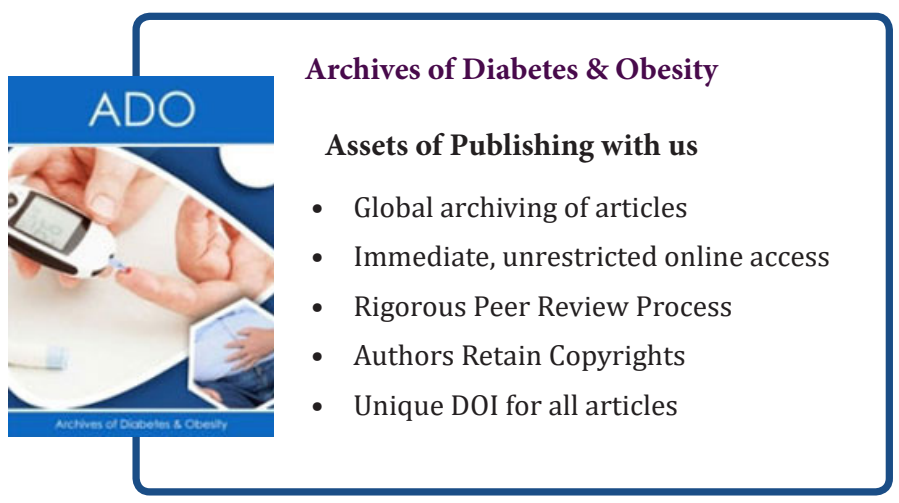

